\title{
THE ESTIMATION OF AVAILABLE PHOSPHORIC ACID IN MANURES.
}

\author{
By W. F. Sutherst, Ph.D., A.I.C. \\ (Read at the Meeting, December 3, 1902.)
}

SiNcE the introduction of the insoluble phosphatic manures, such as basic slag, a method for determining the amount of phosphoric acid which plants are capable of assimilating from them, and also the rate at which this takes place, has not yet been found to work with absolute precision owing to the very great difficulty in imitating such physiological processes in the laboratory.

It had been proved years ago that there were different states in which phosphates existed in the soil and in manures. One soil might contain as much phosphoric acid as another, but on the one soil a much poorer yield of the same kind of crop would be obtained than on the other. The earlier agricultural chemists, such as Liebig, Lawes, and Gilbert, found that when a soil was treated with weak acids, more especially organic acids, only a portion of the total phosphates was dissolved, and in some cases practically none; and from these observations, on comparing the soils giving up small quantities of phosphoric acid to such solvents with the crops grown on them, they found that the more plant food there was dissolved out of a soil by a weak solution of an organic acid the heavier would be the crop obtained from it. These were the first notices of the relation between the total plant food in a soil and the amount available.

A number of standard solutions were suggested to represent the assimilating power of the plant, and in Germany one of these-viz., ammonium citrate--has been generally adopted for both soil and manure analysis.

In England one of the most rational solvents has been brought out by Dr. Dyer, based on the acidity of the plant roots themselves. The results of analyses of numerous varieties showed the average acidity to correspond to about a 1 per cent. citric acid solution; and, from experiments carried out by Dr. Dyer on the Rothamsted soils, it was found that the quantities of potash, phosphoric acid, etc., dissolved out from the soil by this solution were about equal to those absorbed by the crops. This was the first suggested solvent which had been based on actual comparison of the root sap and also yield of crop. Such a solvent might possess the same degree of acidity as the root sap of most species of plants, but it would not have the same chemical composition, since the acidity is due to various acid salts of organic acids, in addition to other substances which might also have the power of dissolving substances such as phosphate of lime out of the soil. To see how far these acid salts were represented 
by the action of citric acid, solutions of potassium binoxalate, bitartrate, and bimalate (whose strength was made equal to a 1 per cent. citric acid solution, except in the case of the bitartrate, which needed diluting down to enable it to dissolve), and various insoluble phosphatic manures-viz., basic slag, basic superphosphate, precipitated phosphate, and mineral phosphate-were mixed together, and at the end of forty-eight hours the amount of phosphoric acid dissolved was estimated. The method employed was as follows: One gramme of each manure was placed in a flask, and to this was added an amount of potassium binoxalate, bitartrate, and bimalate corresponding in degree of acidity to 1 gramme of citric acid, dissolved in 100 c.c. of distilled water (the bitartrate needed, however, 300 c.c. water for solution). After standing for forty-eight hours, with repeated agitation, half the liquid was filtered off, and in this the phosphoric acid was determined by the ammonium molybdate and magnesia mixture method. The following results were obtained :

I. Potassium Binoxalate as Solvent.

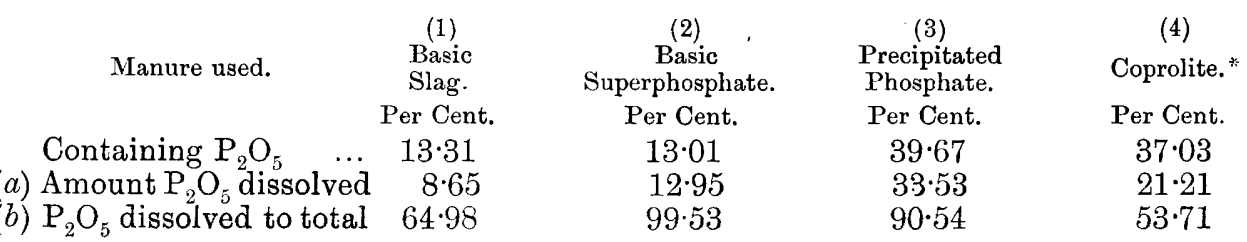

II. Potassium Bitartrate as Solvent.

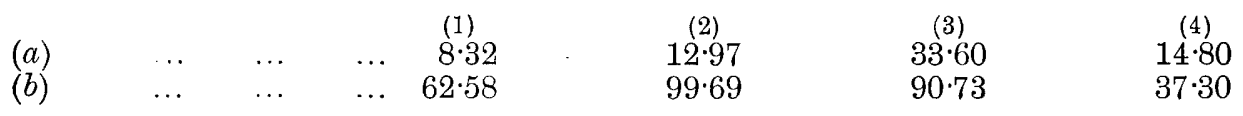

III. Potassium Bimalate as Solvent.

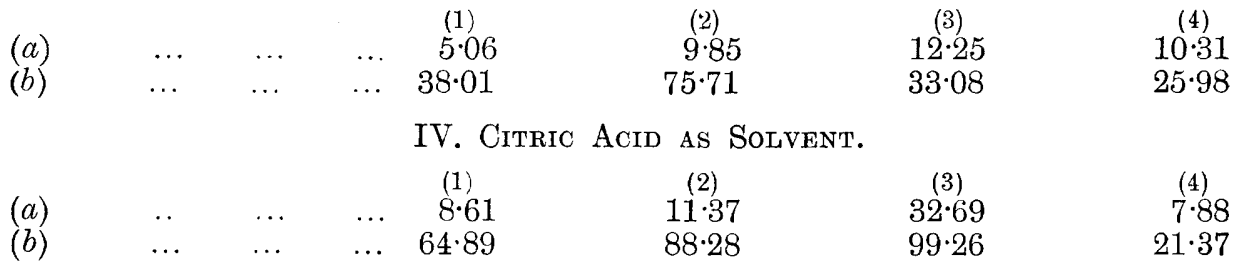

From the above results it will be seen that two of the solvents act in practically the same manner as the citric acid solution, but the other solvent-the potassium malate-appears to have a much weaker power than the others.

The proposed standard, then, evidently represents to a great extent the acid bodies in the root sap, with regard to their power of dissolving the insoluble phosphatic fertilizers and the phosphates in the soil ; but does the method of carrying out the estimation of the available phosphoric acid really represent the manner in which assimilation of plant food takes place? The sap in the rootlets, coming into contact with particles of soil and abstracting from these certain ingredients, must be subjected to a process of continual renewal, since there is a flow of liquid through the plant system from the roots to the leaves, brought about chiefly by evaporation of water

\footnotetext{
* By coprolite the author evidently means mineral phosphate.
} 
from the leaves exposed to the sun's heat. When a fertilizer, such as basic slag, is subjected to analysis for available phosphoric acid by either the citric acid or ammonium citrate method by allowing the solvent to remain in contact with a weighed portion of it, although the flask is rotated or agitated continually, the sample is only acted upon by the same solvent, whose strength must consequently be considerably reduced by the time a portion of the substance is dissolved. It occurred to me that by treating the same sample of a fertilizer with fresh quantities of citric acid solution this would approximately correspond to the renewal of sap in the roots. The method used was as follows: Three grammes each of basic slag and mineral phosphate were placed in 500 c.c. flasks, and to these 300 c.c. 1 per cent. citric acid solution added, and after standing for forty-eight hours, with continual agitation, the amount of $\mathrm{P}_{2} \mathrm{O}_{5}$ dissolved was estimated in 50 c.c. of the liquid. The remaining liquid was then poured off, and the residue treated further with 300 c.c. citric acid solution, and the method repeated as before till very little more $\mathrm{P}_{2} \mathrm{O}_{5}$ was dissolved. The results obtained were as follows :

\begin{tabular}{|c|c|c|c|}
\hline \multirow[t]{2}{*}{ Repeated ACtion o } & $1 \mathrm{PER}$ & Cent. Citric & Acid Solution. \\
\hline & & Basic Slag. & Coprolite. \\
\hline First extraction & & $\begin{array}{c}\text { Per Cent. } \\
8.612\end{array}$ & $\begin{array}{c}\text { Per Cent. } \\
7 \cdot 401\end{array}$ \\
\hline Second extraction & $\ldots$ & 1.536 & $5 \cdot 108$ \\
\hline Third extraction & $\ldots$ & $1 \cdot 276$ & $4 \cdot 834$ \\
\hline Fourth extraction & & $1 \cdot 021$ & $3 \cdot 442$ \\
\hline Fifth extraction & $\ldots$ & $0 \cdot 764$ & $2 \cdot 308$ \\
\hline Sixth extraction & $\ldots$ & - & 1.536 \\
\hline Seventh extraction & $\ldots$ & - & $1 \cdot 102$ \\
\hline Eighth extraction & $\ldots$ & $\ldots$ & 0.964 \\
\hline
\end{tabular}

Since the basic slag contained 13.31 per cent. $\mathrm{P}_{2} \mathrm{O}_{5}$ and the coprolite 37.03 per cent., it will be seen that from the former practically the whole amount is extracted after five extractions, while from the coprolite, though the analyses were not carried on so far, the greater part of the phosphoric acid was taken out in eight repetitions, and in a very regular manner. It appears from the above results that practically the whole of the phosphoric acid in any manure is available for plant food, but that in some it is assimilable in a shorter time than others. Whether the usual method of testing the available plant food and the results obtained by it give any definite idea of the amount a plant is capable of absorbing or not, it seems from the experiments carried out that there is certainly a relation between the amount dissolved and the amount which is in an easy assimilable form, since the large proportion of phosphoric acid dissolved out of the basic slag by one treatment with citric acid as distinguished from that removed from coprolite in proportion to the total present easily accounts for the more rapid effect of basic slag on a crop than that of a ground mineral phosphate.

Discussion.

Dr. Dyer said that a solution of citric acid, of course, was necessarily not quite the same thing as the acid solution in root sap, which no doubt contained a mixture of acid salts. Still, he thought there was this to be said for a citric acid solution, as 
compared with some of these definite acid salts : that while each of these had one definite hydrogen equivalent-one definite acidity-citric acid had three, which possessed different degrees of intensity; so that when one was neutralized, the other two had less than two-thirds of the original acid intensity, while when two were neutralized there remained less than half of this, and possibly citric acid might thus afford a sort of good average acidity. Of course, however, the whole matter was largely arbitrary. Referring to the author's results, he was surprised that citric acid (which in the case of basic slag appeared to have very much the same action as the solutions of acid salts employed) should be found to dissolve so much less phosphoric acid from the basic superphosphate of Mr. Hughes. Mr. Hughes had found that a citric acid solution, even of much less than 1 per cent. strength, dissolved a larger proportion of the phosphoric acid than had been dissolved in the author's experiment in this particular case. It struck him as being a point in favour of the use of citric acid, that, in the case of the ground coprolite, which was well known to be a slowly-acting and difficultly-available manure, the result shown in the paper was in direct accord with the slower action of the coprolite as compared with the known activity of the other manures mentioned.

Mr. John Hughes said that, with regard to the sample of coprolite referred to in the paper, he would like to mention that the materiai in question really consisted of Christmas Island phosphate, as he had learned from the author in the course of correspondence relating to some results which had been previously published in the Chemical News. He (Mr. Hughes) agreed with Dr. Dyer in preferring, as far as his experience had gone, the use of dilute citric acid solution as a solvent in determining the amount of available plant food in manures. There seemed something very appropriate in the use of a vegetable acid for such a purpose. As to what exact strength should be used in future, he ventured to think that considerable latitude might yet be taken before a standard was definitely fixed upon. When Dr. Dyer first suggested that a 1 per cent. solution should be regarded as the standard, that was naturally regarded as a very weak solution; but, as he (Mr. Hughes) had already pointed out elsewhere, the figures given in Dr. Dyer's original paper showed that, out of 103 samples of root sap, the acidity in the case of 27 samples was equivalent to more than 1 per cent. of citric acid, in 49 samples to between 0.5 per cent. and 1 per cent., while in 27 samples the acidity was equivalent to less than 0.5 per cent. of citric acid. On looking further into these figures, it appeared that nearly all the farm crops-wheat, barley, oats, perennial rye grass, Italian rye grass, white turnips, swedes, mangolds, smooth-stalked meadow grass, sheep's fescue grass, foxtail grass, dogtail grass--showed an acidity corresponding on the average with about 0.5 per cent. of citric acid. He ventured to think, therefore, that, if solubility in a 1 per cent. solution were taken as a standard of availability, it must be regarded rather as too high than as too low. In analysing manure he would suggest that, if anything, the standard fixed should be one that was absolutely below the acidity of any known plants grown on the farm, and for this reason he had suggested a 0.1 per cent. solution, which represented an acidity below that of any of the 103 plants analysed by Dr. Dyer. He had found by experience in analysing the various manures mentioned that a solution of that strength gave a large amount 
of solubility, and yielded figures which he thought might fairly be taken as representing the amount of available plant food in those manures.

Mr. Hehner desired to ask Dr. Dyer whether he still adhered to his original suggestion that a connection existed between the acidity of the root sap of plants and their power of absorbing plant food from the soil. Doubtless there were very good reasons for making the experiments which Mr. Hughes had just quoted, and upon which Dr. Dyer had bestowed such a large amount of labour; but it seemed to him that, whereas those experiments had reference to the acidity of the juices within the plant, the solution of the plant food constituents must surely be effected mainly by conditions which lay outside of the functions of the plant proper.

Mr. Seyler thought it would be well that the question should be approached from the physical point of view of the extent to which the acid solvent was ionized. The degree of solution would depend to a greater extent upon the degree of ionization than upon the existence of a certain equivalent acidity taken towards an indicator. This had been found to be the case by Ostwald, who had determined the strength of several organic acids by their solvent action on calcium oxalate. It would seem that the attention of agricultural chemists should be directed towards the selection of a solution having the same degree of ionization as the root sap, rather than one having the same absolute acidity.

Dr. Dyer said that when he first turned his attention to this subject, literature in reference to it had been accumulating for many years, and the general consensus of opinion among agricultural chemists was that, for purposes of soil analysis, if results were to be obtained which indicated in any kind of way the amount of available mineral plant food in soils, they should be obtained by the use of some weak acid solution. There were, however, differences of opinion as to the strength of acid that should be used. He had been led to think about investigating the acidity of the root sap by the experiments of Sachs, who many years ago had grown plants in soil in which polished slabs of marble were buried, with the result that the marble became etched wherever the roots went. .Sachs came to the conclusion that the juices of the roots exuded as they travelled along, and so dissolved and absorbed the carbonate of lime. As Mr. Hughes had very correctly remarked, in a large number of plants the acidity of the root sap was equivalent to less than 1 per cent. of citric acid, but in a good many it represented more, 1 per cent. being about the average. The use of a 1 per cent. citric acid solution having been already proposed-though not with reference to the same question - by a chemist of such authority as Stutzer, it had seemed undesirable that a fresh solution should be chosen as long as the one already proposed appeared to meet the case. This method of dealing with the matter, however, must be regarded as arbitrary, simply because it was never possible to work under soil conditions. The soil was really swamped with root sap solution-if it might for the moment be so called-whereas the roots of plants could only apply their sap as they went along, assuming that to be really the mode of action. The test, therefore, did not really imitate the actual processes of Nature; but it was an attempt to place the investigation of the matter on some kind of rational basis.

Mr. Hehner said that, while the experiments of Sachs certainly indicated the exudation of acid by the roots, yet every living cell exuded carbonic acid, and the 
carbonic acid would fully account for the etching of a polished marble surface. If it were the case that the solution of plant food was due to the acidity of the root sap, other than free carbonic acid, it would seem that the amount of phosphoric acid absorbed by plants from a soil containing an excess of phosphates ought to vary according to their sap acidity, and he would like to ask whether, in Dr. Dyer's experience, this was the case.

Dr. Dyen said that he could not speak precisely with regard to phosphoric acid, but with regard to potash an instance occurred to him which seemed to bear upon Mr. Hehner's question. For some years past, in connection with some field experiments, he had been growing strawberries, among other plants, under different manurial conditions; and, although strawberries demanded a great deal of potash, it had been found in these field experiments that they could be grown year after year without any manurial application of potash, on a soil which was naturally poor as regards that constituent, and on which almost all the other plants grown were grateful for it. He sometimes thought that this was possibly because the root sap of the strawberries (which was among the most acid of those he had examined) was so vigorous that this plant could get potash where others could not. Other rosaceous plants examined agreed with the strawberry plant in showing a very high root sap acidity.

The President (Dr. Voelcker) said that, while undoubtedly at the time of its introduction there were good grounds for believing that the action of a weak acid solution imitated what took place in Nature, botanists were now altogether opposed to the idea that actual excretion from the roots occurred, or that the amount of plant food taken up was dependent upon the acidity of the root sap. The question was one that could not be satisfactorily settled without botanical as well as chemical investigation. With regard to the methods suggested in the present paper, he certainly thought that if potash compounds were tried as solvents, compounds containing other bases ought to be tried also. Dr. Sutherst's general conclusion seemed to be that potassium binoxalate and potassium bitartrate gave practically the same results as citric acid; but, from the figures given, it appeared that, although this was so in the case of basic slag, in the case of the so-called "coprolite" 21 per cent. of the total phosphoric acid was dissolved by citric acid, while as much as 53 per cent. was dissolved by potassium binoxalate, intermediate results being yielded by potassium bitartrate. In the case of the basic superphosphate the results showed the divergence to which attention had been called by Dr. Dyer, namely, that, while 88 per cent. of the phosphoric acid was dissolved by dilute citric acid, $99 \frac{1}{2}$ per cent. was dissolved by potassium binoxalate. In the second part of the paper the author suggested that, inasmuch as the plant with its acid sap would take up certain materials, a regular change must go on in the character of the sap, and that, in dissolving the soil constituents, an attempt might be made to imitate that change by using the various solvents mentioned in successive doses. There seemed no doubt, however, that, if such treatment were carried far enough, complete solution could be effected in every case. He had heard with interest Mr. Hughes's remark as to the nature of the "coprolite" referred to, because he had only recently heard it contended that the material known as "Christmas Island Phosphate" would be more properly described as "guano." 